\title{
Variation in the Size of Eggs of Kelp Gulls (Larus dominicanus) at Two Colonies in Patagonia, Argentina
}

\author{
Walter S. Svagelj ${ }^{1, *}$, Nora Lisnizer ${ }^{2}$, Pablo García Borboroglu ${ }^{2,3}$ and Pablo Yorio ${ }^{2,4}$ \\ ${ }^{1}$ Instituto de Investigaciones Marinas y Costeras - CONICET, Universidad Nacional de Mar del Plata - UNMdP, \\ Dean Funes 3250, Mar del Plata (B7602AYJ), Buenos Aires, Argentina
}

${ }^{2}$ Centro Nacional Patagónico - CONICET, Boulevard Brown 2915, Puerto Madryn (U9120ACD), Chubut, Argentina

${ }^{3}$ University of Washington, Department of Biology, Box 351800, Seattle, Washington, 98195-1800, USA

${ }^{4}$ Wildlife Conservation Society, Amenábar 1595, Ciudad de Buenos Aires (C1426AKC), Argentina

"Corresponding author; E-mail: titosvagelj@hotmail.com

\begin{abstract}
Although several studies have reported basic information about the size of Kelp Gull (Larus dominicanus) eggs, no attention has been paid to the comparison of patterns of intra-clutch variation at different breeding sites. Here, the variation in egg size of Kelp Gulls at two colonies from Patagonia, Argentina, was analyzed. The objectives were to characterize egg size variation in Kelp Gulls breeding at a recently established colony in Punta Loma that primarily relies on natural prey; and to evaluate if patterns of intra-clutch variation in that colony differ from those at Vernaci Sudoeste Island, a larger and well-established colony with access to supplementary food in the form of fishery waste. In two-egg clutches, first-eggs were larger than second-eggs. Neither average egg size nor intra-clutch patterns differed between study sites. Also, in two-egg clutches, egg size decreased as date of laying increased, probably due to younger birds laying smaller eggs later in the season. The pattern of intra-clutch variation in three-egg clutches differed between sites. Three-egg clutches at Vernaci Sudoeste Island presented similar sizes for first- and second-eggs and these were larger than third-eggs. This pattern contrasted with the steady decrease in relation to laying order that was observed at Punta Loma. Also, secondand third-eggs from Vernaci Sudoeste Island were larger than corresponding eggs from Punta Loma. Our data suggest that differences in egg size between colonies could be the consequence of enhanced food availability at Vernaci Sudoeste Island in the form of discards generated by trawl fisheries. Future studies to evaluate age of birds and inter-annual environmental stochasticity are needed to elucidate the effect of these factors on egg size variation. Received 5 April 2014, accepted 13 November 2014.
\end{abstract}

Key words.- - egg laying order, egg mass, egg variation, food availability, intra-clutch variation, Kelp Gull, Larus dominicanus.

Waterbirds 38(1): 92-98, 2015

The study of intra-specific variation in egg size is of biological interest because egg size varies greatly within bird species and has important implications for offspring quality and survival (Christians 2002). Egg production is a nutritionally demanding process (Williams 2005) that can be limited by the quantity and quality of food available to the female during clutch formation. Several studies on gulls suggested that average egg size is reduced under poor feeding conditions (Pierotti and Bellrose 1986; Sydeman and Emslie 1992). Experimental evidence that food can limit egg production in gulls has come from food supplementation studies that resulted in increases in egg size (Reid 1987; Bolton et al. 1992). In addition, nutritional or energetic constraints operating on the laying female also have been invoked to explain patterns of intra-clutch egg-size variation (Järvinen and Ylimaunu 1986; Pierotti and Bellrose 1986). Such constraints may be especially noticeable where egg size declines with laying order because the relative size of the last egg in the clutch is presumed to depend on nutritional condition and energy reserves of the laying female (Järvinen and Ylimaunu 1986; Pierotti and Bellrose 1986; Kilpi et al. 1996). If so, patterns of intra-clutch variation in egg size could differ between colonies according to prevailing food conditions, which vary in space and time.

Most gull species (Laridae) produce a typical clutch of three eggs where the thirdlaid egg is the smallest of the clutch (Reid 1987). Pierotti and Bellrose (1986) suggested that variation in egg size in gulls may be due to variation in female energy reserves and predicted that in colonies where food 
is abundant, differences in egg size within clutches may be reduced or even absent. Moreover, Kilpi et al. (1996) suggested that the size of the last egg in the clutch reflects the feeding potential in the environment and is mainly a non-adaptive response to prevailing feeding conditions during egg formation.

The Kelp Gull (Larus dominicanus) is widely distributed in the southern hemisphere, breeding in Australia, New Zealand, southern Africa, South America, subantarctic islands and the Antarctic Peninsula (Burger and Gochfeld 1996). Kelp Gulls are generalist and opportunistic feeders that take advantage of artificial food sources, such as fisheries discards and urban refuse (Yorio et al. 2005). In Patagonia, Argentina, the Kelp Gull is the most abundant gull species (Yorio et al. 1999), with an estimated total population of over 98,000 breeding pairs (Yorio et al. 1998; Lisnizer et al. 2011). Several studies have reported basic information about the size of Kelp Gull eggs (Williams $e t$ al. 1984; Yorio and García Borboroglu 2002; Branco et al. 2009). However, no attention has been paid to the comparison of patterns of intra-clutch variation between different breeding sites.

Yorio and García Borboroglu (2002) described basic aspects of egg size variation in a large and well-established Kelp Gull colony located at Vernaci Sudoeste Island, San Jorge Gulf, Patagonia, Argentina. Important Argentine hake (Merluccius hubbsi) and Argentine red shrimp (Pleoticus muelleri) trawl fisheries that operate year round in the vicinity of Vernaci Sudoeste Island provide significant amounts of supplementary food to Kelp Gull populations in the form of fishery waste (González-Zevallos and Yorio 2006; González-Zevallos et al. 2011).

Our objectives were to: 1) characterize egg size variation in Kelp Gulls breeding at a recently established colony in Punta Loma (Lisnizer et al. 2014), which primarily relies on natural prey; and 2) evaluate if patterns of intra-clutch variation in that colony differ from those at Vernaci Sudoeste Island.
Methods

Study Area

The Punta Loma Protected Area $\left(42^{\circ} 49^{\prime} \mathrm{S}, 64^{\circ} 47^{\prime}\right.$ W) is located $15 \mathrm{~km}$ from the city of Puerto Madryn, Patagonia, Argentina. Kelp Gulls first nested at this location in 2004 (Lisnizer et al. 2014). The abundance of breeding pairs increased rapidly during the first years since the colony established, reaching about 100 breeding pairs by 2006 (Lisnizer et al. 2014). Punta Loma is located approximately $18 \mathrm{~km}$ from the Puerto Madryn refuse tip, and no fisheries operate close to the area. Kelp Gulls from Punta Loma include waste from processing plants in their diets, but in a relatively minor proportion (M. Ricciardi and P. Yorio, unpubl. data).

Vernaci Sudoeste Island ( $\left.45^{\circ} 11^{\prime} \mathrm{S}, 66^{\circ} 31^{\prime} \mathrm{W}\right)$ has an area of approximately 6.4 ha and is located at San Jorge Gulf National Park, Patagonia, Argentina. Kelp Gulls are the most abundant seabird species breeding on the island; their numbers have increased from 6,300 to 9,200 breeding pairs between 1995 and 2006 (Yorio $e t$ al. 1998; Lisnizer et al. 2011). Similar or higher population trends were observed for other Kelp Gull colonies in that coastal sector (Lisnizer et al. 2011).

\section{Data Collection}

Data from Punta Loma correspond to the 2006 and 2007 breeding seasons, while data from Vernaci Sudoeste Island were collected during 1998 and 1999. From September to December, we collected information on timing of nest initiation, laying dates, clutch size, egg size and laying order. Only first clutches were included in this study. We marked eggs with a felt-tip pen, identifying the order in which it was laid. We measured the length and breadth of the eggs with calipers to the nearest $0.1 \mathrm{~mm}$. In total, we measured $962 \mathrm{eggs}$ from 408 clutches (Punta Loma: 114 and 108 clutches in 2006 and 2007, respectively; Vernaci Sudoeste Island: 92 and 94 clutches in 1998 and 1999, respectively).

\section{Statistical Analysis}

We calculated egg mass from egg-length and breadth measurements using the formula: Egg mass = $K_{\mathrm{m}} \times$ Length $\times$ Breadth $^{2}$ (Hoyt 1979), where $K_{\mathrm{m}}$ is a species-specific mass coefficient determined from 30 eggs measured and weighed within 3 days of when they were laid $\left(K_{\mathrm{m}}=5.34 \times 10^{-4} \mathrm{~g} \mathrm{x} \mathrm{mm}^{-3}\right)$. Calculated egg mass explained $94.8 \%$ of the fresh-egg mass $\left(r=0.974, F_{1,28}=\right.$ $515, P<0.0001$ ), so we used calculated mass as a reliable estimator of egg size.

To test the effects of laying order, study site, and laying date (hereafter, explanatory variables) and their interactions on egg mass, we employed linear mixed models (Pinheiro and Bates 2000). We included 'year' (four levels: 1998, 1999, 2006 and 2007) and 'nest identity' nested in year (nest number, a unique code for each nesting attempt) as random effects.

To properly evaluate the interaction terms between laying order and other predictor variables, we conducted separate analyses for two- and three-egg clutches. 
Egg laying order was included as a factor with first-, second- and third-laid eggs coded as $a$-, $b$-and $c$-eggs, respectively. Study site (Punta Loma or Vernaci Sudoeste Island) was included as a two-level factor. Laying date was standardized across years before inclusion, entering it as a deviation from the median laying date of the relevant year and dividing the result by the standard deviation for that year. Due to logistical limitations, laying order could not be determined for some clutches; therefore, those clutches were excluded from our statistical analyses. Laying order was known for 124 and 138 two- and three-egg clutches, respectively.

Statistical analyses were carried out using Program R (R Development Core Team 2013). Values were reported as means $\pm \mathrm{SE}$, except where noted. All tests were two-tailed, and differences were considered significant at $P<0.05$.

\section{Results}

Overall, mean egg mass at Punta Loma was $87.9 \mathrm{~g}(\mathrm{SD}=7.8 \mathrm{~g}, \mathrm{CV}=8.9 \%, n=461$ eggs from 222 clutches). Egg mass ranged from 67.6 to $121.7 \mathrm{~g}$, the largest egg being $80 \%$ heavier than the smallest. Egg length ranged from 60.6 to $81.7 \mathrm{~mm}$ (mean $=70.8$ $\mathrm{mm}, \mathrm{SD}=3.1, n=461)$ and breadth from 44.1 to $52.8 \mathrm{~mm}($ mean $=48.2 \mathrm{~mm}, \mathrm{SD}=1.5$, $n=461$ ). At Punta Loma, we measured eggs in 222 clutches, but knew clutch size and sequence of laying in only 155 of them (Table
1). First-laid ( $a-)$ eggs were heavier than the $b$-eggs in $65 \%(91 / 141)$ of clutches, while the $c$-eggs were the lightest in $98 \%(80 / 82)$ of clutches.

In two-egg clutches, $a$-eggs were heavier than $b$-eggs (data from both colonies pooled; $a$-eggs: $90.6 \pm 0.7 \mathrm{~g}$; $b$-eggs: $88.6 \pm 0.5 \mathrm{~g}$; Table 2). Egg mass decreased as date of laying increased $(\beta=-1.61 \pm 0.79$; Table 2$)$. The decrease in egg mass with laying date did not differ with laying order (Table 2; Fig. 1). Also, the decrease in egg mass with laying order did not differ between study sites (Table 2; Fig. 2A). There was no variability between years within colonies, as the random effect of year was non-significant (Table 2).

In three-egg clutches, the pattern of intra-clutch variation in relation to laying order differed between study sites (Table 2; Fig. 2B). At Punta Loma, egg mass progressively decreased with the order in which eggs were laid ( $a$-eggs $-b$-eggs: $z=2.36, P$ $=0.048 ; a$-eggs $-c$-eggs: $z=19.7, P<0.001$; $b$-eggs $-c$-eggs: $z=17.3, P<0.001$; Fig. $2 \mathrm{~B}$ ) At Vernaci Sudoeste Island, egg mass did not differ between $a$ - and $b$-eggs ( $a$-eggs $b$-eggs: $z=-0.76, P=0.73)$, while both were heavier than $c$-eggs ( $a$-eggs $-c$-eggs: $z=11.8$, $P<0.001 ; b$-eggs $-c$-eggs: $z=12.5, P<0.001$;

Table 1. Length $(\mathrm{mm})$, breadth $(\mathrm{mm})$ and mass $(\mathrm{g})$ (mean $\pm \mathrm{SD}$; GV in parentheses) of Kelp Gull (Larus dominicanus) eggs from Punta Loma colony in relation to laying sequence and clutch size. First-, second-, third- and fourthlaid eggs were coded as $a$-, $b$-, $c$ - and $d$-eggs, respectively.

\begin{tabular}{|c|c|c|c|c|}
\hline \multirow[b]{2}{*}{ Clutch Size } & \multicolumn{4}{|c|}{ Egg Laying Order } \\
\hline & $a$-eggs & $b$-eggs & c-eggs & $d$-eggs \\
\hline \multicolumn{5}{|c|}{ One-egg clutches $(n=13)$} \\
\hline Egg length (mm) & $71.0 \pm 3.5(4.9)$ & & & \\
\hline Egg breadth (mm) & $47.7 \pm 1.5(3.1)$ & & & \\
\hline Egg mass $(\mathrm{g})$ & $86.4 \pm 8.0(9.3)$ & & & \\
\hline \multicolumn{5}{|c|}{ Two-egg clutches $(n=59)$} \\
\hline Egg length (mm) & $71.3 \pm 3.2(4.5)$ & $70.8 \pm 3.0(4.2)$ & & \\
\hline Egg breadth $(\mathrm{mm})$ & $48.6 \pm 1.4(2.9)$ & $48.1 \pm 1.3(2.7)$ & & \\
\hline Egg mass $(\mathrm{g})$ & $90.1 \pm 7.9(8.8)$ & $87.6 \pm 7.1(8.1)$ & & \\
\hline \multicolumn{5}{|c|}{ Three-egg clutches $(n=82)$} \\
\hline Egg length (mm) & $72.2 \pm 2.8(3.9)$ & $71.2 \pm 2.6(3.7)$ & $69.4 \pm 2.8(4.0)$ & \\
\hline Egg breadth $(\mathrm{mm})$ & $48.8 \pm 1.2(2.5)$ & $48.8 \pm 1.0(2.0)$ & $47.0 \pm 1.2(2.6)$ & \\
\hline Egg mass $(\mathrm{g})$ & $91.9 \pm 6.5(7.1)$ & $90.7 \pm 5.7(6.3)$ & $82.0 \pm 6.2(7.6)$ & \\
\hline \multicolumn{5}{|c|}{ Four-egg clutches $(n=1)$} \\
\hline Egg length (mm) & 71.5 & 72.1 & 65.3 & 68.3 \\
\hline Egg breadth (mm) & 47.8 & 47.2 & 45.0 & 46.1 \\
\hline Egg mass $(\mathrm{g})$ & 87.4 & 85.5 & 70.5 & 77.3 \\
\hline
\end{tabular}




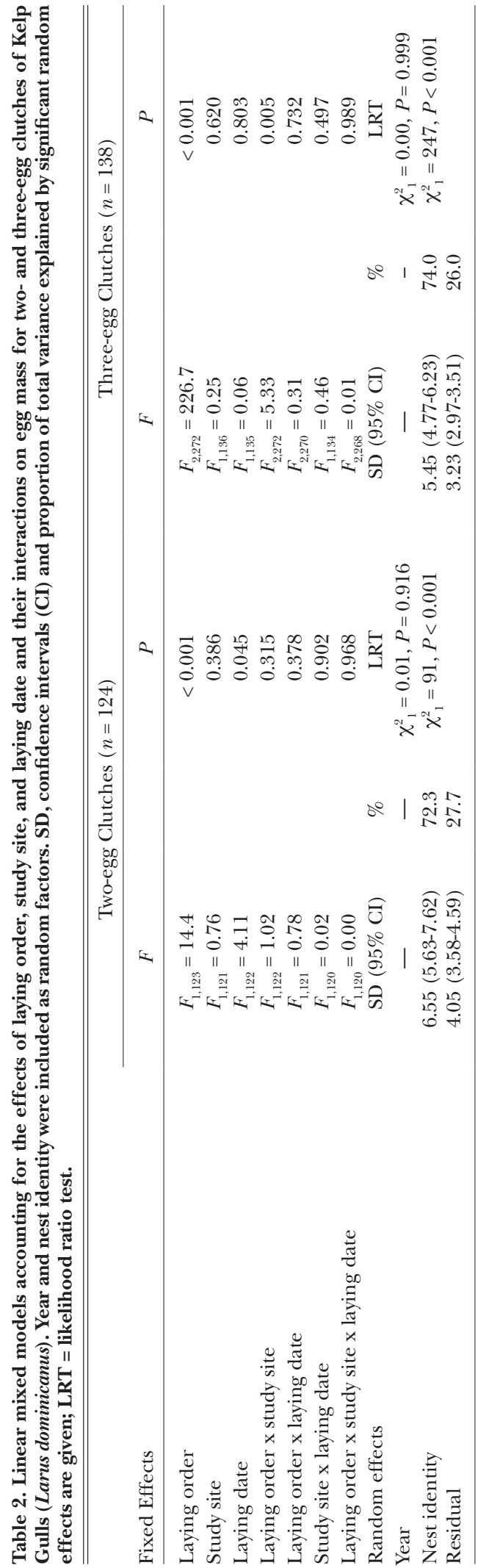

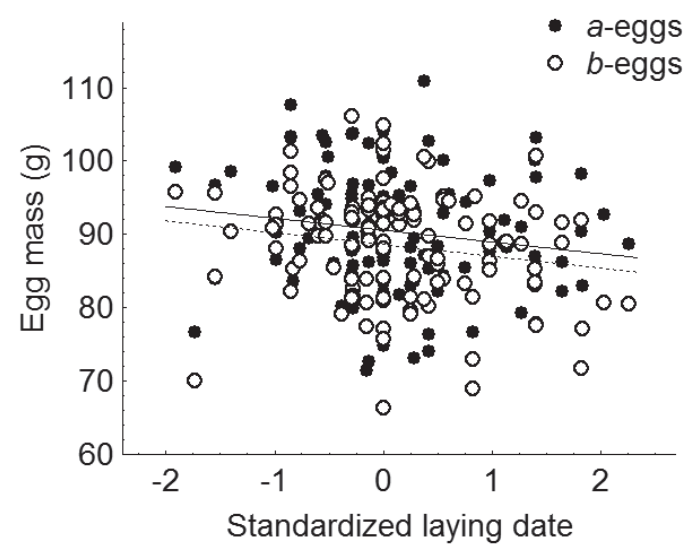

Figure 1. Relationship between standardized laying date and estimated mass of eggs of Kelp Gulls (Larus dominicanus) for first- and second-eggs in two-egg clutches ( $n$ $=124)$. First- and second-laid eggs were coded as $a$ - and $b$-eggs, respectively. Adjusted functions for $a$ - and $b$-eggs are Egg mass $=90.6-1.61 x$ and Egg mass $=88.6-1.61 x$, respectively.

Fig. 2B). In addition, while mass of $a$-eggs did not differ between study sites $(z=0.5, P=$ $0.63), b$ - and $c$-eggs from Vernaci Sudoeste Island were heavier than corresponding eggs from Punta Loma (b-eggs: $z=2.1, P=0.035$; $c$-eggs: $z=2.8, P<0.01$; Fig. 2B). The random effect of year was not significant (Table 2).

\section{Discussion}

Overall, the length, breadth and mass of eggs from Punta Loma were within the range reported for the species (Williams et al. 1984; Yorio and García Borboroglu 2002; Branco et al. 2009). Also, at both studied colonies, egg mass decreased with laying sequence with $c$ eggs being lighter than $a$ - and $b$-eggs, which is in consonance with the typical pattern exhibited by gulls (Bolton et al. 1992; Sydeman and Emslie 1992; but see Pierotti and Bellrose 1986), in general, and by the Kelp Gull (Williams et al. 1984; Branco et al. 2009), in particular.

Pierotti and Bellrose (1986) proposed that variation in egg size in gulls may be due to variation in female energy reserves, and that in colonies where food is abundant, the amount of egg size variation within clutches would be reduced. These authors found that 

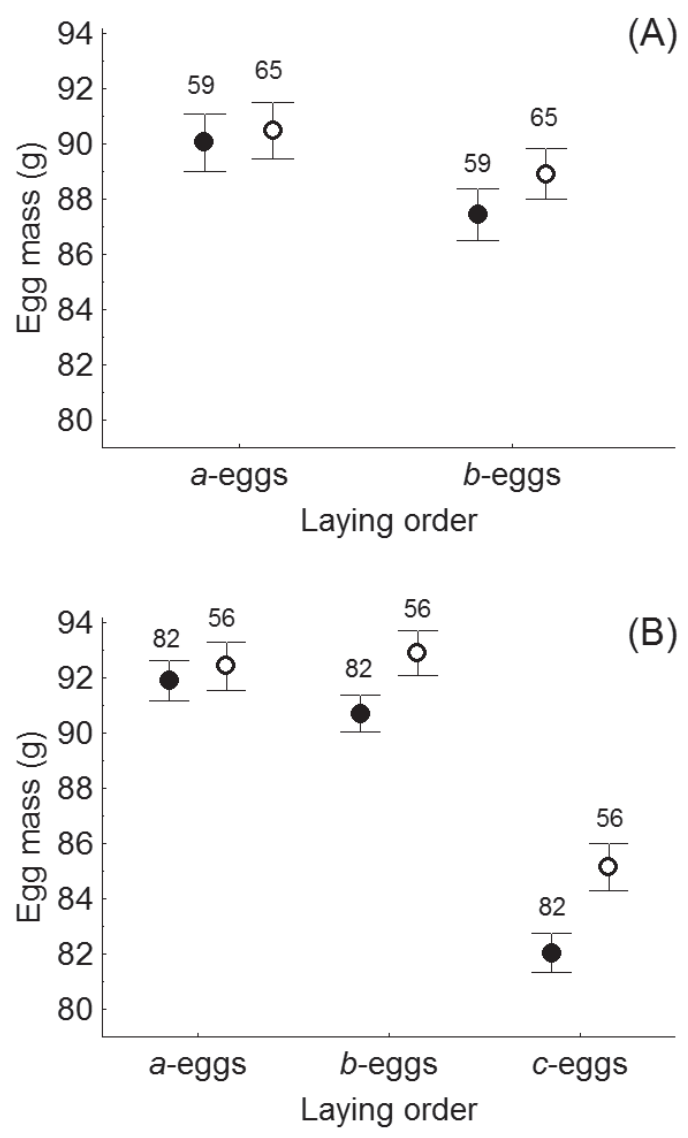

Punta Loma

Vernaci Sudoeste Island

Figure 2. Mean estimated mass of eggs of Kelp Gulls (Larus dominicanus) in relation to laying order and study site (Punta Loma or Vernaci Sudoeste Island) for (A) two-egg clutches $(n=124)$ and $(B)$ three-egg clutches $(n$ $=138$ ). First-, second- and third-laid eggs were coded as $a$-, $b$ - and $c$-eggs, respectively. Numbers indicate sample size; whiskers show $\mathrm{SE}$.

Western Gulls (L. occidentalis) breeding in a colony with a superabundant food supply laid the largest eggs ever reported for that species (Pierotti and Bellrose 1986). Moreover, Pierotti and Bellrose (1986) reported that $c$-eggs were as large as $a$ - and $b$-eggs. In a study carried out on the same species but in a large and dense population with pelagic feeding habits, Sydeman and Emslie (1992) found the typical pattern where $c$-eggs were smaller than $a$ - and $b$-eggs. Also, these authors found that the magnitude of intraclutch variation in egg size depended on environmental conditions probably related to food availability. In that study, intra-clutch differences between $a$ - and $c$-eggs were more pronounced in years of poor food availability (Sydeman and Emslie 1992).

Our study shows that at two-egg clutches, $a$-eggs were heavier than $b$-eggs, which was in accordance with the pattern exhibited by other Kelp Gull populations (Williams et al. 1984). Neither average egg mass nor pattern of intra-clutch variation differed between sites for two-egg clutches. Also in two-egg clutches, we found that egg mass decreased as date of laying increased, likely due to younger birds laying lighter eggs later in the season (Moreno 1998; Christians 2002).

At three-egg clutches, our results suggest a differential pattern of intra-clutch variation at the two studied colonies. Three-egg clutches at Vernaci Sudoeste Island presented similar masses for $a$ - and $b$-eggs, and these were heavier than $c$-eggs. This pattern contrasted with the steady decrease in relation to laying order that was observed for threeegg clutches at Punta Loma. Furthermore, $b$ - and $c$-eggs in three-egg clutches from Vernaci Sudoeste Island were heavier than corresponding eggs from Punta Loma. While the diet of Kelp Gulls from Punta Loma is mostly based on natural sources (M. Ricciardi and P. Yorio, unpubl. data), Kelp Gulls from Vernaci Sudoeste Island take advantage of significant amounts of fishery waste provided by commercial trawlers, which have operated in the vicinity year round since the 1980s (González-Zevallos and Yorio 2006; González-Zevallos 2010; González-Zevallos et al. 2011). The consumption of fishery waste could enhance female body condition, resulting in an increase in egg size. In several seabird species, fishery waste has been shown to affect breeding parameters, including egg size (Oro 1999). Supplemental food in the form of fisheries discards and urban refuse has also been mentioned as a possible factor that has driven population increases in the San Jorge Gulf area during the last 2 decades (Lisnizer et al. 2011).

Even though our data suggest that differences in egg mass between colonies could be a consequence of differences in food 
availability between study sites, we cannot rule out two alternative explanations. First, some studies in new colonies of gulls and terns reported that they were mainly composed by young breeders (Coulson and White 1956; Tims et al. 2004). Because egg size increases with age in several bird species (see Christians 2002 for a review), lighter eggs at Punta Loma, compared to those from an old-established colony at Vernaci Sudoeste Island, could be the consequence of a higher proportion of young breeders. Unfortunately, age of birds was not known in our study, and future research evaluating the effect of age on egg mass is needed to clarify this point. Second, as data collection at Vernaci Sudoeste Island and Punta Loma was 7 years apart, differences in egg mass could be the consequence of yearly variations in sea conditions. It must be noted, however, that there was no inter-annual variability in egg mass within colonies. Even though we only sampled two breeding seasons in each colony, our results suggest a low temporal variation probably as a consequence of conserved environmental conditions or consistent food availability at the study sites. Long term studies simultaneously analyzing Kelp Gull egg size, food availability and diet are needed to elucidate this issue.

\section{ACKNOWLEDGMENTS}

Research was funded by grants from the PNUDGEF-02/018, FONCYT and PICT-33611, CONICET and Wildlife Conservation Society. We thank Centro Nacional Patagónico for institutional support. We thank Chubut provincial authorities for the permits to work at the protected areas (21/06-DFyFS, 21/07-DFyFS, 053/06-DGCAP, 167/07-SSTyAP). The manuscript benefited from the constructive comments of two anonymous referees.

\section{Literature Cited}

Bolton, M., D. Houston and P. Monaghan. 1992. Nutritional constraints on egg formation in the Lesser Black-backed Gull: an experimental study. Journal of Animal Ecology 61: 521-532.

Branco, J. O., H. A. A. Fracasso and E. Barbieri. 2009. Breeding biology of the Kelp Gull (Larus dominicanus) at Santa Catarina coast, Brazil. Ornitologia Neotropical 20: 409-419.

Burger, J. and M. Gochfeld. 1996. Family Laridae (gulls). Pages 572-623 in Handbook of the Birds of the World, vol. III: Hoatzin to Auks (J. del Hoyo, A. Elliott and J. Sargatal, Eds.). Lynx Edicions, Barcelona, Spain.

Christians, J. K. 2002. Avian egg size: variation within species and inflexibility within individuals. Biological Reviews 77: 1-26.

Coulson, J. C. and E. White. 1956. A study of colonies of the Kittiwake Rissa tridactyla. Ibis 98: 63-79.

González-Zevallos, D. 2010. Aprovechamiento del descarte en las principales pesquerías del golfo San Jorge. Doctoral Thesis, Universidad Nacional del Comahue, Río Negro, Argentina.

González-Zevallos, D. and P. Yorio. 2006. Seabird use of discards and incidental captures at the Argentine hake trawl fishery in the Golfo San Jorge, Argentina. Marine Ecology Progress Series 316: 175-183.

González-Zevallos, D., P. Yorio and W. S. Svagelj. 2011. Seabird attendance and incidental mortality at shrimp fisheries in Golfo San Jorge, Argentina. Marine Ecology Progress Series 432: 125-135.

Hoyt, D. F. 1979. Practical methods of estimating volume and fresh weight of bird eggs. Auk 96: 73-77.

Järvinen, A. and J. Ylimaunu. 1986. Intraclutch egg-size variation in birds: physiological responses of individuals to fluctuations in environmental conditions. Auk 103: 235-237.

Kilpi, M., L. Hillström and K. Lindström. 1996. Egg-size variation and reproductive success in the Herring Gull Larus argentatus: adaptive or constrained size of the last egg? Ibis 138: 212-217.

Lisnizer, N., P. García Borboroglu and P. Yorio. 2011. Spatial and temporal variation in population trends of Kelp Gulls in northern Patagonia, Argentina. Emu 111: 259-267.

Lisnizer, N., P. García Borboroglu and P. Yorio. 2014. Demographic and breeding performance of a new Kelp Gull Larus dominicanus colony in Patagonia, Argentina. Ardeola 61: 3-14.

Moreno, J. 1998. The determination of seasonal declines in breeding success in seabirds. Etología 6: $17-31$.

Oro, D. 1999. Trawler discards: a threat or a resource for opportunistic seabirds? Proceedings of the International Ornithological Congress 22: 717-730.

Pierotti, R. and C. A. Bellrose. 1986. Proximate and ultimate causation of egg size and the "third-chick disadvantage" in the Western Gull. Auk 103: 401-407.

Pinheiro, J. C. and D. M. Bates. 2000. Mixed-effects models in S and S-Plus. Springer, New York, New York.

R Development Core Team. 2013. R: a language and environment for statistical computing v. 3.0.2. R Foundation for Statistical Computing, Vienna, Austria. http://www.R-project.org/, accessed 24 February 2014.

Reid, W. V. 1987. Constraints on clutch size in the Glaucous-winged Gull. Studies in Avian Biology 10: 8-25.

Sydeman, W. J. and S. D. Emslie. 1992. Effects of parental age on hatching asynchrony, egg size and third-chick disadvantage in Western Gulls. Auk 109: 242-248. 
Tims, J., I. C. T. Nisbet, M. S. Friar, C. Mostello and J. J. Hatch. 2004. Characteristics and performance of Common Terns in old and newly-established colonies. Waterbirds 27: 321-332.

Williams, A. J., J. Cooper and P. A. R. Hockey. 1984. Aspects of the breeding biology of the Kelp Gull at Marion Island and in South Africa. Ostrich 55: 147-157.

Williams, T. D. 2005. Mechanisms underlying the costs of egg production. BioScience 55: 39-48.

Yorio, P. and P. García Borboroglu. 2002. Breeding biology of Kelp Gulls (Larus dominicanus) at Golfo San Jorge, Patagonia, Argentina. Emu 102: 257-263.
Yorio, P., M. Bertellotti and P. García Borboroglu. 2005. Estado poblacional y de conservación de gaviotas que se reproducen en el litoral marítimo Argentino. Hornero 20: 53-74.

Yorio, P., M. Bertellotti, P. Gandini and E. Frere. 1998. Kelp Gulls Larus dominicanus breeding on the Argentine coast: population status and relationship with coastal management and conservation. Marine Ornithology 26: 11-18.

Yorio, P., E. Frere, P. Gandini and W. Conway. 1999. Status and conservation of seabirds breeding in Argentina. Bird Conservation International 9: 299-314. 